\title{
Is hospital care involved in inequalities in coronary heart disease mortality? Results from the French WHO-MONICA Project in men aged $30-64$
}

Thierry Lang, Pierre Ducimetière, Dominique Arveiler, Philippe Amouyel, Jean Ferrières, Jean Bernard Ruidavets, Michèle Montaye, Bernadette Haas, Annie Bingham

\begin{abstract}
Objectives-The goal of the study was to assess whether possible disparities in coronary heart disease (CHD) management between occupational categories (OC) in men might be observed and contribute to the increasing inequalities in CHD morbidity and mortality reported in France. Methods-The data from the three registers of the French MONICA Collaborative Centres (MCC-Lille, MCC-Strasbourg, and MCC-Toulouse) were analysed during two periods: 1985-87 and 1989-91. Acute myocardial infarctions and coronary deaths concerning men, aged 30-64 years, were included. Non-professionally active and retired men were excluded. Results were adjusted for age and MCC, using a logistic regression analysis.
\end{abstract}

Results-605 and 695 events were analysed for 1985-87 and 1989-91, respectively. Out of hospital cardiac arrests, with or without cardiac resuscitation, and 28 day case fatality rates were lower among upper executives in both periods. A coronarography before the acute event had been performed more frequently in men of this category and the proportion of events that could be hospitalised was higher among them. In both periods, the management of acute myocardial infarctions in hospital and prescriptions on discharge were similar among occupational categories.

Conclusions-For patients who could be admitted to hospital, the management was found to be similar among OCs, as was the 28 day case fatality rate among the hospitalised patients. In contrast, lower prognosis and higher probability of being hospitalised after the event among some categories suggest that pre-hospital care and the patient's conditions before the event are the primary factors involved. (f Epidemiol Community Health 1998;52:665-671)

Increasing disparities in coronary heart disease (CHD) mortality and morbidity have been observed between socioeconomic categories for the past 20 years in several industrialised countries. ${ }^{1-3}$ Understanding the reasons for these trends is required to tackle this public health problem. Many contributing factors have been identified or suspected. The role of the general social and economic evolution of societies, facing unemployment and job instability, the growing importance of private sphere compared with public domain especially in Eastern countries, have been emphasised. ${ }^{4}$ The role of classic cardiovascular risk factors (hypertension, cigarette smoking, cholesterol) has been evaluated and has been found to account only partially for the disparities observed. ${ }^{3}$ In France, hypertension control and tobacco smoking, unlike cholesterol and HDLcholesterol concentrations, were shown to account, at least partly, for the social disparities in coronary events distribution between categories. ${ }^{5}$ It should be emphasised that these disparities concern incidence as well as case fatality rates. ${ }^{5}$ As the efficacy of coronary care has improved dramatically during the past 10 years, some variations related to care might be involved. Strong differences in health care utilisation have been observed between occupational categories (OCs) in France despite a wide system of health insurance coverage, the "Sécurité Sociale". ${ }^{6-8}$ Persons from lower classes tend to underuse preventive care as well as specialised health care services. They consult more often general practitioners than specialists. $^{67}$ Increasing copayment by the patients in the past 10 years in France ${ }^{8}$ might have reinforced the cultural and educational factors at the origin of these different behaviours. Finally, even within the health care structure, socioeconomic variations in health delivery or quality of care have been reported. ${ }^{9} 10$

Data on routine medical care delivered for acute myocardial infarction (AMI) episodes have been collected since 1985 in three French medical regions, within the framework of the MONICA Project. ${ }^{11}$ These data, standardised and prospectively collected, provide a good insight into both use and delivery of coronary care.

Using these data, the goal of our study was thus to assess whether possible disparities in CHD management between OCs might be observed and contribute to the increasing inequalities in CHD morbidity and mortality reported in the French active population.

\section{Methods}

REGISTERS

Three MCCs have participated in the WHO MONICA Project in France: MCC-Lille (LIL), MCC-Strasbourg (STR), and MCCToulouse (TOU). The geographical areas are respectively the Urban Community of Lille 
Table 1 Characteristics of the patients, clinical and non-clinical findings at the first examination and prognosis in the two periods

\begin{tabular}{|c|c|c|c|}
\hline & $1985-87$ & 1989-91 & $p$ Value \\
\hline Number & 605 & 695 & \\
\hline Age $(y)$ & $51.4(8.3)$ & $50.1(8.3)$ & $<0.001$ \\
\hline Smokers (\%) & 66.9 & 62.3 & NS \\
\hline \multicolumn{4}{|l|}{ First measurement after the event } \\
\hline Systolic blood pressure $(\mathrm{mm} \mathrm{Hg})$ & $136.2(33.3)$ & $138.8(33.2)$ & $<0.001$ \\
\hline Heart rate (beat/min) & $88.4(20.6)$ & $90.9(21.1)$ & $<0.001$ \\
\hline Creatinine phosphokinase (UI) & $945(986)$ & $943(948)$ & NS \\
\hline ALAT & $446(452)$ & $548(725)$ & $<0.001$ \\
\hline \multicolumn{4}{|l|}{ Electrocardiographic finding } \\
\hline Q wave $(\%)$ & 40.9 & 39.2 & NS \\
\hline changes in anterior leads (\%) & 37.3 & 45.1 & $<0.01$ \\
\hline \multicolumn{4}{|l|}{ Cardiac arrest } \\
\hline before admission $(\%)$ & 19.9 & 20.4 & NS \\
\hline within the hospital (\%) & 12.8 & 10.1 & NS \\
\hline Death at 28 days $(\%)$ & 27.6 & 25.7 & NS \\
\hline \multicolumn{4}{|l|}{ Cases admitted to hospital } \\
\hline Number (\%) & $506(83.6)$ & $580(83.4)$ & NS \\
\hline Admitted to intensive care unit (ICU) (\%) & 92.8 & 94.6 & NS \\
\hline Total length of stay in hospital & $14.8(8.9)$ & $14.4(9.3)$ & $<0.05$ \\
\hline Length of stay in ICU & $6.7(4.6)$ & $6.2(5.3)$ & $<0.001$ \\
\hline Death at 28 days $(\%)$ & 13.9 & 10.5 & NS \\
\hline
\end{tabular}

Data shown as mean (SD) and percentages.

(LIL) and two French districts: Bas-Rhin (STR), Haute-Garonne (TOU), of about one million inhabitants each. The MCCs collect data on mortality and incidence of myocardial infarction and on medical care within 28 days after the onset of the acute event. This data collection concerns the subjects living in the geographical area and in the 25-64 years age range. The details of the protocol have been published elsewhere. ${ }^{11}$ Briefly, all efforts are made to recruit the events through a systematic screening of private and public hospitals as well as death certificates, including sudden death certificates. All the suspected events are reviewed by trained staff. Data are collected from the medical record. When it is unavailable, interviews are performed and information is collected during hospitalisation. An event is included as a new event if its apparent onset took place more than 28 days after any previous coronary event. Record linkage was used during this 28 day period to avoid duplication. Cardiac arrests were recorded and a distinction was made between pre-hospital and within hospital cardiac arrests. Technical definitions from the MONICA manual have been published in detail. ${ }^{11}$ Diagnostic criteria included symptoms, history of previous AMI or CHD, electrocardiograms, enzyme activities, and necropsy findings. Coronary events were designated as fatal and non-fatal according to the date of death, before or after midnight between the 27th and the 28th day after the first event. Two different case fatality rates were analysed: (1) 28th day case fatality rate among all events and (2) 28th day case fatality rate in the sub-population of events who did not die before hospital admission and could be admitted to hospital. External quality control was performed by the WHO Reference Centre in Dundee (Professor Tunstall Pedoe) and the MONICA Data Center in Helsinki. ${ }^{11}$ In addition, strict standardisation and quality assurance were monitored locally and between the three French centres.

The data from the registers were analysed during two periods: $1985-87$ and $1989-91$. No data had been recorded on medical care in
1988. MONICA events classified as category 1 (definite AMI) and deaths in category 2 (coronary death) were used for this analysis. The proportion of these two categories did not differ between OCs. All events concerning men, aged 30-64 years, were included. Nonprofessionally active and retired men were excluded. Given the small size of this group, farmers were not included in the analysis.

CLASSIFICATION OF OCCUPATIONAL CATEGORIES Socioeconomic categories were coded in each region according to the INSEE (French National Statistical Institute) classification. ${ }^{12}$ Information was collected from the medical record, from administrative files or near the relatives of the patient. Five categories were used in this analysis: craftsmen, upper executives, middle executives, employees, and workers. The INSEE classification, widely used for research and administrative purposes, has been in existence since the 19th century in France. The notions of trade associations, the distinction between public and private sectors and, recently, the hierarchy among wage earners have been progressively added to build this present measurement of social class. The categories have thus been built along three axes: occupation, income, and education. This classification has been described in detail previously. ${ }^{2}$ Employees and workers have roughly the same income. Employees are defined negatively as working neither in the industrial, nor in the agricultural or craft sector and are mostly - but not exclusively-non-manual workers. The income increases progressively from middle executives, farmers and craft persons to upper executives. The educational level of employees, which is higher than that of workers, has increased less than that of the general population in the past 30 years. $^{2}$

CORONARY CARE

Information was collected on medical treatments in the 28 days preceding the onset of the event. Procedures such as coronary angioplasty, coronary angiography, and bypass surgery were registered if they had been performed at any time before the event. Drugs and procedures are those prescribed or performed during the hospital stay, at any time after admission, in the subgroup of patients who were hospitalised. The medications on discharge concern the medications or procedures prescribed on the day of discharge. Information on survival was systematically surveyed 28 days after the acute event.

\section{STATISTICAL ANALYSIS}

The analysis was performed among all cases as far as prognosis, admission to hospital, medical treatments and procedures before the events were concerned. Medical management during the event was analysed only in the subgroup of patients who have been hospitalised. Qualitative variables were compared between groups, using the $\chi^{2}$ test. The length of hospital stay was compared after a logarithmic transformation. To test the hypothesis that OC was related to the performance of a specific procedure, two 
Table 2 Procedures and drug treatment before, during, and after the event in 1985-87 and 1989-91

\begin{tabular}{|c|c|c|c|c|c|c|}
\hline \multirow[b]{2}{*}{$\begin{array}{l}\text { Procedures and drug } \\
\text { treatments }\end{array}$} & \multicolumn{3}{|l|}{$1985-87$} & \multicolumn{3}{|l|}{ 1989-91 } \\
\hline & $\begin{array}{l}\text { Before the } \\
\text { event }\end{array}$ & $\begin{array}{l}\text { During } \\
\text { hospitalisation }\end{array}$ & $\begin{array}{l}\text { On } \\
\text { discharge }\end{array}$ & $\begin{array}{l}\text { Before the } \\
\text { eventt }\end{array}$ & $\begin{array}{l}\text { During } \\
\text { hospitalisationt }\end{array}$ & $\begin{array}{l}\text { On } \\
\text { discharget }\end{array}$ \\
\hline Inotropic agents & 3.3 & 21.4 & 3.5 & 1.7 & $17.1^{\star \star \star}$ & 2.1 \\
\hline Nitrates & 19.9 & 92.6 & 71.4 & 17.3 & $52.3^{\star \star \star}$ & 68.9 \\
\hline Diuretics & 10.1 & 25.5 & 12.1 & 8.4 & 26.6 & 10.1 \\
\hline Antiarrhythmic agents & 3.7 & 50.1 & 14.4 & 3.4 & 49.5 & $8.0^{\star \star}$ \\
\hline Anticoagulants & 6.0 & 91.4 & 46.0 & 5.6 & 93.2 & $39.2^{\star}$ \\
\hline Antiplatelet agents & 7.3 & 26.9 & 34.0 & $3.6^{\star \star}$ & 31.1 & 29.1 \\
\hline Aspirin & - & - & - & - & 83.9 & 76.1 \\
\hline$\beta$ blockers & 16.2 & 47.5 & 43.5 & 17.0 & $69.2^{\star \star \star}$ & $64.1^{\star \star \star}$ \\
\hline Calcium channel blockers & 13.9 & 70.1 & 66.0 & 15.7 & $44.1^{\star \star \star}$ & $31.1^{\star \star \star}$ \\
\hline ACE inhibitors & - & - & - & 9.2 & 24.5 & 20.4 \\
\hline Hypolipidaemic agents & - & - & - & 12.3 & 12.9 & 14.6 \\
\hline Fibrinolytic agents & - & 25.7 & - & - & $47.7^{\star \star \star}$ & - \\
\hline \multicolumn{7}{|l|}{ Coronary } \\
\hline angiography & 13.1 & 57.6 & 21.9 & $17.1 \ddagger$ & $77.9^{\star \star \star}$ & $10.3^{\star \star \star}$ \\
\hline angioplasty & 1.8 & 11.3 & 1.9 & $4.6^{\star \star}$ & $33.3^{\star \star \star}$ & 3.9 \\
\hline Bypass surgery & 2.7 & 5.6 & 7.6 & 3.5 & 4.8 & 5.8 \\
\hline Formal rehabilitation & - & - & 32.0 & - & - & $45.6^{\star \star \star}$ \\
\hline
\end{tabular}

†Statistical significance of the differences between the two periods: $\neq \mathrm{p}<0.1 ;{ }^{\star \star} \mathrm{p}<0.01 ;{ }^{\star \star \star} \mathrm{p}<0.001$.

logistic models were compared: one included age, MCC, and period; the second one included age-in three age groups-, MCC, period, and four dummy variables for the five OCs. The likelihood of these two models were then compared. ${ }^{13}$ If the model with OCs was significantly different from the other one, the relative risks of receiving a drug or undergoing a procedure in a given OC was then estimated by odds ratios (ORs). Middle executives were used as the reference group for the four other OCs. Statistical analysis was performed with the SAS statistical package. ${ }^{14}$

\section{Results}

ACUTE MYOCARDIAL INFARCTION AND CORONARY CARE IN THE WHOLE POPULATION IN 1984-87 AND 1989-91

Six hundred and five events in 1984-87 and 695 events in 1989-91 were analysed (table 1). In the second period, patients tended to be younger and a higher percentage of events with changes in the anterior leads was observed on the ECG. Among all events, a cardiac arrest occurred for one event out of five. A cardiac arrest was recorded in $80.1 \%$ of the fatal events. These percentages remained stable from one period to the other. The case fatality rate was also similar in the two periods. Death occurred at 28 days for one event out of four.

The delay between symptoms and first care was not reduced significantly (mean (SD) 4.5 (10.6) hours in 1985-87 compared with 3.6 (8.9) hours in 1989-91, NS). An increased utilisation of emergency care mobile units was observed $(25.1 \%$ in $1985-87$ compared with $37.2 \%$ in $1989-91, \mathrm{p}<0.001)$. However, the percentage of patients admitted to hospital or to the intensive care unit was stable between the two periods. The total length of hospital stay decreased slightly, whereas the length of stay in ICU decreased significantly (table 1). Death occurred at 28 days for one of 10 events who could be admitted to hospital. Within the hospital a cardiac arrest was recorded for one of 10 events.

Table 3 Prognosis, procedures, and treatments according to occupational categories

\begin{tabular}{|c|c|c|c|c|c|c|}
\hline & $\begin{array}{l}\text { Craftsmen } \\
(n=95) \\
\%(95 \% C I)\end{array}$ & $\begin{array}{l}\text { Upper } \\
\text { executives } \\
(n=127) \\
\%(95 \% C I)\end{array}$ & $\begin{array}{l}\text { Middle } \\
\text { executives } \\
(n=212) \\
\%(95 \% C I)\end{array}$ & $\begin{array}{l}\text { Employees } \\
(n=161) \\
\%(95 \% C I)\end{array}$ & $\begin{array}{l}\text { Workers } \\
(n=412) \\
\%(95 \% C I)\end{array}$ & $p$ Value \\
\hline Cardiac arrest before admission & $23(8)$ & $12(6)$ & $25(5)$ & $21(6)$ & $23(4)$ & 0.04 \\
\hline Alive at day 28 & $68(9)$ & $84(6)$ & $69(6)$ & $71(7)$ & $69(4)$ & 0.01 \\
\hline $\begin{array}{l}\text { Hospitalised } \\
\text { Procedure during hospital stay }\end{array}$ & $82(7)$ & $90(5)$ & $79(5)$ & $83(5)$ & $80(4)$ & 0.08 \\
\hline Inotropic agents & $33(9)$ & $16(6)$ & $25(6)$ & $22(6)$ & $25(4)$ & 0.08 \\
\hline Nitrates & $89(6)$ & $94(4)$ & $83(5)$ & $89(5)$ & $88(3)$ & 0.07 \\
\hline Diuretics & $32(9)$ & $22(7)$ & $16(5)$ & $22(6)$ & $28(4)$ & 0.005 \\
\hline Antiarrhythmic agents & $52(10)$ & $52(9)$ & $43(7)$ & $44(8)$ & $46(5)$ & 0.4 \\
\hline Anticoagulants & $87(7)$ & $88(6)$ & $80(5)$ & $87(5)$ & $85(3)$ & 0.23 \\
\hline Antiplatelet agents & $38(10)$ & $37(8)$ & $27(6)$ & $26(6)$ & $26(4)$ & 0.03 \\
\hline Aspirin $\star$ & $80(12)$ & $79(10)$ & $74(8)$ & $77(9)$ & $74(5)$ & 0.15 \\
\hline$\beta$ blockers & $45(10)$ & $61(8)$ & $50(7)$ & $54(8)$ & $57(5)$ & 0.08 \\
\hline Calcium channel blockers & $44(10)$ & $61(8)$ & $53(7)$ & $48(8)$ & $51(5)$ & 0.13 \\
\hline ACE inhibitors * & $22(12)$ & $14(9)$ & $22(8)$ & $26(9)$ & $22(5)$ & 0.51 \\
\hline Fibrinolytic agents & $30(9)$ & $36(8)$ & $34(6)$ & $32(7)$ & $32(5)$ & 0.91 \\
\hline Coronary & & & & & & \\
\hline angiography & $58(10)$ & $68(8)$ & $64(6)$ & $61(8)$ & $62(5)$ & 0.51 \\
\hline angioplasty & $25(9)$ & $27(8)$ & $18(5)$ & $24(6)$ & $19(4)$ & 0.19 \\
\hline Bypass surgery & $4(4)$ & $9(5)$ & $4(3)$ & $3(3)$ & $4(2)$ & 0.1 \\
\hline Prescriptions on discharge & $(n=73)$ & $(n=111)$ & $(n=170)$ & $(n=132)$ & $(n=333)$ & \\
\hline Nitrates & $64(11)$ & $71(8)$ & $68(7)$ & $68(8)$ & $68(5)$ & 0.12 \\
\hline Antiplatelet agents & $45(11)$ & $37(9)$ & $33(7)$ & $33(8)$ & $30(5)$ & 0.88 \\
\hline$\beta$ blockers & $56(11)$ & $59(9)$ & $52(8)$ & $57(8)$ & $56(5)$ & 0.32 \\
\hline ACE inhibitors ${ }^{\star}$ & $15(11)$ & $15(9)$ & $15(8)$ & $20(9)$ & $24(6)$ & 0.32 \\
\hline Formal rehabilitation & $39(11)$ & $40(9)$ & $44(7)$ & $43(8)$ & $45(5)$ & 0.81 \\
\hline
\end{tabular}

^Period 1989-91 only. 
Table 4 Procedures performed before the acute event according to occupational categories

\begin{tabular}{lllllll}
\hline \multicolumn{7}{c}{ Occupational category } \\
\cline { 2 - 5 } & $\begin{array}{l}\text { Craftsmen } \\
\left(\begin{array}{l}n=108) \\
\%(95 \% C I)\end{array}\right.\end{array}$ & $\begin{array}{l}\text { Upper } \\
\text { executives } \\
(n=133) \\
\%(95 \% C I)\end{array}$ & $\begin{array}{l}\text { Middle } \\
\text { executives } \\
(n=244) \\
\%(95 \% C I)\end{array}$ & $\begin{array}{l}\text { Employees } \\
\left(\begin{array}{l}n=186) \\
\%(95 \% C I)\end{array}\right.\end{array}$ & $\begin{array}{l}\text { Workers } \\
(n=481) \\
\%(95 \% C I)\end{array}$ & $p$ Value \\
\hline $\begin{array}{c}\text { Coronary } \\
\text { angiography } \\
\text { angioplasty }\end{array}$ & $18(7)$ & $24(7)$ & $15(4)$ & $15(5)$ & $11(3)$ & 0.01 \\
Bypass surgery & $5(4)$ & $7(4)$ & $0(1)$ & $3(2)$ & $3(2)$ & 0.01 \\
\hline
\end{tabular}

Table 2 shows the treatments and procedures that have been analysed. Among medical treatments, fibrinolytic agents, and $\beta$ blockers during the hospital stay and on discharge were used increasingly from the first to the second period. Calcium channel blockers, in contrast, were less used in 1989-91 than in 1985-87. Among procedures, the use of angiography during the hospital stay increased from 1985-87 to 1989-91 and its use after discharge from the hospital decreased. Angioplasty was increasingly performed before the event and during hospitalisation. In contrast, bypass surgery frequency did not show any major change with time (table 2).

CHARACTERISTICS AND MANAGEMENT OF AMI ACCORDING TO OCCUPATIONAL CATEGORIES Adverse events and prognosis of AMI

Out of hospital cardiac arrests, with or without cardiac resuscitation, were lower among upper executives in both periods $(12.7$ and $11.5 \%$ compared with 22.8 and $23.9 \%$ respectively in the whole active population. The OR adjusted for age, MCC, and period was $0.40(\mathrm{p}<0.01)$ for upper executives (tables 3 and 4). During both periods, the 28 day case fatality rate was lower among upper executives in both periods (19.4 and $12.3 \%$ compared with 31.0 and $30.1 \%$ respectively in other categories of the population (adjusted OR: 0.39, p<0.001) (tables 3 and 5).

Medical treatment and procedures before the acute event

Although previous angina, AMI or acute coronary event were not reported more frequently in any OC $(18 \%)$, a coronary angiography had been performed more often among upper executives $(18.0 \%$ in 1985-87 and $30.2 \%$ in $1989-91$; OR: $1.81, \mathrm{p}<0.05$ ), compared with 12.1 and $14.9 \%$ respectively in other OCs. The same was true for angioplasty $(6.6 \%$ and $7.9 \%$. OR: $15.9, \mathrm{p}<0.01)$, com-
KEY POINTS

- After an acute coronary event, 28 day survival rates were higher among upper executives, because of a higher probability of surviving during the pre-hospital phase, and a lower frequency of cardiac arrests during this phase.

- Among the sub-population of patients who survived the pre-hospital phase after an acute coronary event and thus could be admitted to hospital, 28 day survival rates, hospital management of the event, drug prescription, and procedures did not differ between occupational categories (OCs).

- In contrast, a higher frequency of coronary angiography and angioplasty before the acute coronary event suggests that ambulatory management of patients was different, more procedures being performed among upper OCs.

- More attention and more data are needed concerning the ambulatory management of coronary diseases and the pre-hospital phase to reduce inequalities in coronary mortality between OCs.

pared with 0.9 and $3.7 \%$ in other OCs (tables 4 and 5). The results obtained after exclusion of events with a previous AMI were similar (data not shown).

The use of other antihypertensive agents, the association between diuretics and inotropic drugs, $\beta$ blockers, calcium channel inhibitors or nitrate agents did not differ between OCs. Before the event, a diuretic treatment had been prescribed more often in two categories, the employees ( $11.4 \%$ in $1985-87$ and $10.0 \%$ in 1989-91; OR: 3.41, p<0.01), and workers $(12.6 \%$ and $9.4 \%$ respectively; OR: 3.03 , $\mathrm{p}<0.01$ ), compared with 6.7 and $5.4 \%$ respectively in other OCs.

\section{Access to acute care, hospitalisation and severity of $A M I$}

The delays between symptoms and first care or hospitalisation, the percentage of cases for which the emergency care mobile teams was called, did not differ between OCs. Among all events, $83.7 \%$ were hospitalised in 1985-87 and $83.4 \%$ in $1989-91$. The proportion of events that could not be hospitalised was lower among upper executives (13.4\% in 1985-89

Table 5 Prognosis, procedures, and treatments according to occupational categories. Odds ratio from a logistic regression analysis, adjusted for age, period, and region

\begin{tabular}{|c|c|c|c|c|c|}
\hline \multirow[b]{2}{*}{ Proceduret } & \multicolumn{5}{|c|}{ Occupational category odds ratio $(95 \%$ CI) } \\
\hline & Craftsmen & Upper executives & Middle executives & Employees & Workers \\
\hline 28 days survival rate & $1.03(0.62,1.69)$ & $2.53^{\star \star \star}(1.46,4.38)$ & 1 & $1.13(0.74,1.73)$ & $1.01(0.72,1.42)$ \\
\hline Diuretic treatment before the event & $2.43(0.90,6.57)$ & $2.32(0.88,6.14)$ & 1 & $3.41^{\star \star}(1.43,8.10)$ & $3.03^{\star \star}(1.40,6.57)$ \\
\hline Cardiac arrest before hospitalisation & $0.85(0.48,1.49)$ & $0.40^{\star \star}(0.22,0.75)$ & 1 & $0.75(0.47,1.20)$ & $0.9(0.62,1.31)$ \\
\hline Coronarography before the event & $1.14(0.60,2.15)$ & $1.81^{\star}(1.03,3.18)$ & 1 & $1.02(0.58,1.79)$ & $0.7(0.44,1.13)$ \\
\hline Angioplasty before the event & $5.84(0.59,57.44)$ & $15.9^{\star \star}(1.97,128.26)$ & 1 & $7.51(0.89,63.38)$ & $6.81(0.88,52.75)$ \\
\hline Being hospitalised & $1.35(0.74,2.44)$ & $2.5^{\star \star}(1.29,4.82)$ & 1 & $1.36(0.83,2.23)$ & $1.06(0.72,1.57)$ \\
\hline Diuretic treatment within hospital & $2.18^{\star \star}(1.21,3.93)$ & $1.38(0.78,2.45)$ & 1 & $1.52(0.89,2.59)$ & $1.91^{\star \star}(1.24,2.95)$ \\
\hline
\end{tabular}

Procedures were included if the model including occupational categories was significantly different from that not including them. The following variables were analysed: cardiac arrest before admission; alive at day 28 ; hospitalised; procedures during hospital stay: inotropic agents, nitrates, diuretics, antiarrhythmic agents, anticoagulants, antiplatelet agents, aspirin, $\beta$ blockers, calcium channel blockers, ACE inhibitors, and fibrinolytic agents; coronary angiography and angioplasty, bypass surgery before the acute event and during hospital stay. ${ }^{\star} \mathrm{p}<0.05 ;{ }^{\star \star} \mathrm{p}<0.01$. 
and $6.2 \%$ in $1989-91$; OR: $0.40, \mathrm{p}<0.01$ ), compared with 38.3 and $20.0 \%$ in other OCs (tables 3 and 5).

The variables that were available to assess the initial severity did not differ between OCs. The percentages of changes in the anterior leads, the presence of a $\mathrm{Q}$ wave on the ECG, the level of enzymes, initial heart rate or blood pressure levels did not differ significantly between OCs.

\section{Management of AMI during hospitalisation}

In both periods, the total duration of hospital stay, and the duration in intensive care did not differ between OCs. Performing coronary angiography, angioplasty or coronary bypass surgery was independent of OC. $\beta$ Blockers, antiplatelet agents, and thrombolytic therapy were used with the same frequency, whatever the OC (tables 3 and 5). Among patients who were admitted to hospital, the 28 day survival did not differ between OCs.

Prescriptions on discharge

In both periods, anticoagulants, $\beta$ blockers, calcium inhibitors, antiarrhythmic treatments, antiplatelet agents, and formal rehabilitation were used with the same frequency in all OCs (tables 3 and 5).

\section{Discussion}

As a whole, the hospital management of acute coronary events was not found to be different between OCs during both periods. The performance of major invasive procedures (angiography, angioplasty) and the use of treatments that proved to be effective in recent years, such as $\beta$ blockers, thrombolytic therapy, antiplatelet agents ${ }^{15}$ were not related to OC. Similarly, the percentage of patients admitted to intensive care units, their duration of stay and prescriptions on discharge were similar among OCs. For patients admitted to hospital, no variation in the case fatality rate was found according to OCs.

In contrast, some differences between OCs were observed concerning the pre-hospital phase. A lower case fatality rate, a lower rate of cardiac arrests, and a lower proportion of events that could not be hospitalised was found in the category of upper executives. One could hypothesise that the time between first symptoms and access to care might depend on OCs. However, the delays between appearance of symptoms and hospital admission as well as the frequency of call of mobile emergency care unit did not vary between OCs. Behaviours do not seem to vary much between OCs in regard to seeking emergency care. The lack of relation between OC and delay in seeking care after symptoms is not surprising in view of previous reports. Education has been reported to neither increase nor decrease delay time. ${ }^{16}$ In contrast, low socioeconomic status has been shown to increase delay time, in countries where health insurance coverage is low among disadvantaged groups. ${ }^{16}$

The importance of resuscitation before admission is suggested in our study, as the proportion of events that could be hospitalised might theoretically be improved for all OCs to that reached for upper executives. This aspect has been observed in other countries. For example, in New Zealand, $16 \%$ of the avoided deaths between 1974 and 1981 were attributed to cardiac resucitation. ${ }^{17}$

The differences concerning the case fatality rate and the use of treatments and investigations might be related to the severity of events or the extent of the atherosclerotic disease. Unfortunately, few data were available to assess the initial severity of events. The percentage of patients under diuretic treatment before the acute event might be related to a higher frequency of cardiac failure, but also to a higher prevalence of treated arterial hypertension. A high percentage in the use of diuretics during the hospital stay suggests a higher severity among craftsmen. A higher severity of events or arterial disease, or both, among some OCs with high fatality rate might thus be one aspect of the findings. If this was true, these findings would further emphasise the importance of the pre-hospital phase. This is true for workers as well as for craftsmen during both periods. Indeed, the use of ambulatory care by this latter category has been reported to be low in France, possibly because of time and financial constraints. ${ }^{6}$

Some limitations of the study should be underlined. Data on OC were obtained from the medical record or the patient's relatives. This variable was thus subject to measurement error. A high frequency of misclassification errors might explain that some differences between OCs might be undetected in our study, because of a lack of power. This effect is probably marginal because with the same methodology, important differences were observed in relation to incidence and case fatality of acute myocardial infarction. ${ }^{25}$ Thus, differences observed between OCs for the incidence with MONICA data, ${ }^{5}$ quite concordant with disparities in mortality ${ }^{2}$ were not observed for hospital care. The second main limitation is the lack of information on the appropriateness of the investigations, procedures, and treatments noted in this study. For example, angiography had been more often performed among upper executives in the last period than among other OCs. The interpretation is not straightforward. This may be because of an excess of inappropriate procedures in this category as well as a lack of necessary procedures in other categories $^{18}$ or, more probably, to both these possibilities.

The evolution between the two periods shows a rapid evolution of the prescriptions in each OC. The rapidity of the diffusion of prescriptions might be related to OC, higher among the more affluent. In our data however, no interaction was observed between OCs and period.

Our results do not show differences in hospital management according to OC. This result is not surprising, although it was not obvious. Such variations in delivery of hospital care have been reported in various countries and health care systems. In the United States, a higher probability of substandard medical care 
has been reported among low socioeconomic status patients. ${ }^{9}$ In the Corpus Christi Heart Project, Mexican Americans received less cardiovascular medications after myocardial infarction than non-Hispanic whites, after adjustment on risk factors and presence of congestive heart failure. ${ }^{19}$ Using national data from Australia, $\operatorname{Scott}^{20}$ has shown that patients of higher socioeconomic status were more likely to receive tests and less likely to receive drug prescriptions than other patients. In France, a high OC has been reported to be associated with more frequent prescription of calcium, iron, vitamin $\mathrm{D}$, and blood transfusions in patients hospitalised for haemodialysis. However, the case fatality rate did not differ between OCs in that study. ${ }^{10}$

Similarly, in our study, the case fatality rate did not differ between OCs among those patients who did not die before admission and thus could be hospitalised. This result is not in contradiction with previous reports showing a reduced survival after myocardial infarction for patients in the lower socioeconomic status or with shorter education ${ }^{21} 22$ or angiographically reported coronary disease. ${ }^{23}$ Indeed, our data relate to the short-term, closely related to hospital care. Psychosocial influences might have a much greater impact on the long term-three years ${ }^{21}$ - or four to six years. ${ }^{22}$ Similarly, poor control of high blood pressure might increase the case fatality rate of AMI in the long term through left ventricular hypertrophy.

This lack of social disparities for the hospital management of AMI are in contrast with the wide regional variations that have been found in France and in United States for these medical procedures. ${ }^{152}$ These results showing a lack of disparities for hospital medical care among hospitalised patients and pointing to prehospital care and conditions are concordant with previous data on health care use by social categories in France. Variations in use of ambulatory care have been shown to be important between OCs. Upper categories tend to use more specialised medicine. ${ }^{67}$ Similarly, prevention has been shown to be lower among categories with a low socioeconomic status. ${ }^{5}$ In contrast with ambulatory care and prevention, the use of hospital care has been shown to be frequent among lower categories in France and even to be a substitute for ambulatory care. ${ }^{6725}$ So, in contrast with ambulatory care, for which patient characteristics are important, use of hospital care seems to be linked mostly to external factors - availability of care and medical practices. ${ }^{24}$ These results are indeed very close to those observed in Finland. In that country, as in France, a debate on inequity in health has been hampered by the belief that universal access to care through a national health insurance system could guarantee equal use of health services. In Finland, the use of hospital services was found to be neutral to socioeconomic status. ${ }^{26}$ In contrast, inequity was observed concerning rates of common surgical procedures, ${ }^{27}$ which were performed in both private and public hospitals. These differences were thought to be related to different referral patterns from ambulatory care to hos- pital. As in France, lower social status patients consult general practitioners and the more affluent consult private specialists. The probability to be referred by these two physicians might thus be different. ${ }^{27}$ It should be kept in mind that our results were obtained among active men. The contrasts between OCs among them might be smaller than those between active and inactive men. Indeed, in an Irish study, the mean duration of medical management before angiography among economically inactive patients was twice as long as for the economically inactive. ${ }^{28}$

In conclusion, for patients who could be admitted to hospital, the management of AMI was found to be similar among OCs. Worse prognosis, lower frequency of cardiac arrests, and higher probability of being hospitalised after the event among some categories suggest that pre-hospital care and patient's conditions before the event are the primary factors involved. Our data suggest that to attain the low incidence and low case fatality rate of AMI that have been reported among upper executives, ${ }^{5}$ further research should focus on the utilisation of ambulatory care, prevention of cardiovascular risk factors, and the general health status of the patients before the acute event. The incidence of cardiac arrests and the proportion of events that can be hospitalised are also possible targets for improvement, focusing on pre-hospital resuscitation. Further improvements in reducing inequalities might come from prevention, ambulatory care, and rapid access to hospital after the event.

We would like to thank the investigators of the three French centres for their invaluable contribution in the careful collection and validation of the data, the physicians and cardiologists who helped in this process, as well as M C Nuttens, J I Salomez, and J L Richard. Funding: this work was supported by a grant from the Institut
National de la Santé et de la Recherche Médicale (INSERM) and from the Direction Générale de la Santé (DGS) Conflicts of interest: none.

1 Marmot MG, McDowall ME. Mortality decline and widening social inequalities. Lancet 1986;ii:274-6.

2 Lang T, Ducimetière P. Premature cardiovascular mortality in France: divergent evolution between social categories between 1970 and 1990. Int $\mathcal{F}$ Epidemiol 1995;24:331-9.

3 Kaplan GA, Keil JE. Socioeconomic factors and cardiovascular disease: a review of the literature. Circulation 1993;88: 1973-98.

4 Watson P. Explaining rising mortality among men in Eastern Europe. Soc Sci Med 1995;41:923-34.

5 Lang T, Ducimetière P, Arveiler D, et al. Occupational categories and cardiovascular risk factors : distinct relationships with incidence and case fatality from acute coronary heart disease.Results from the French WHO-MONICA Project, 1985-89, in men aged 30-59. Int f Epidemiol Project, 1985-89,

6 Charraud A, Mormiche P. Disparités de consommation médicale. Enquête santé 1980-81. Coll. INSEE. Série M. médicale. Enquête sante 1980.8

7 Mizrahi A, Mizrahi A. Les facteurs socio-économiques de la consommation médicale. Biblio No887. Paris: CREDES, 1991

8 Sailly JC, Lebrun T. Où va le système de soins français? Analyse, témoignages, orientations. Lille: CRESGE, 1991.

9 Burstin HR, Lipsitz SR, Brennan TA. Socioeconomic status and risk for substandard medical care. $\mathcal{F} A M A$ 1992;268: 2383-7

10 Rozenbaum W, Degoulet P, Aimé F, et al. Influence de la catégorie socio-professionnelle sur le traitement par hémodiáyse itératice de l'insuffisancé létale chronique avancee. Resultats du programme cooperatif DIAPHANE Dialyse 22 .

11 The WHO MONICA Project. (prepared by Tunstall-Pedoe $\mathrm{H}$, Kuulasmaa $\mathrm{K}$, Amouyel $\mathrm{P}$, et al). Myocardial infarction and coronary deaths in the World Health Organization 
Monica Project. Registration procedures, event rates, and case-fatality rates in 38 populations from 21 countries in four continents. Circulation 1994;90:583-612.

12 INSEE. Nomenclature des professions et catégories socioprofessionnelles. Paris: INSEE, 1983.

13 Bouyer J, Hémon D, Cordier S, et al. Epidémiologie. Principes et méthodes quantitatives. Paris: Inserm Ed, 1993.

14 SAS/STAT user's guide. Version 6, 4th ed. Cary, NC: SAS institute Inc, 1989:846.

15 Amouyel P, Arveiler D, Cambou JP, et al. Myocardial infarction case-fatality gradient in three French regions: the influence of coronary care. Int $\mathcal{F}$ Epidemiol 1994;23:700-9.

16 Dracup K, Moser DK, Eisenberg M, et al. Causes of delay in seeking treatment for heart attack symptoms. Soc Sci Med 1995;40:379-92.

17 Beaglehole R. Medical management and the decline in mortality from coronary heart disease. BMF 1986;292:33-5.

18 Bernstein SJ, Kosecoff J, Gray D, et al. The appropriateness Bernstein SJ, Kosecoff J, Gray D, et al. The appropriateness
of the use of medical procedures. Int $\mathcal{f}$ Technol Assess Health Care 1993;9:3-10.

19 Herholz H, Goff DC, Ramsey DJ, et al. Women and Mexican Americans receive fewer cardiovascular drugs following myocardial infarction than men and non-Hispanic whites: the Corpus Christi Heart Project, 1988-90. F Clin Epidemiol 1996;49:279-87.

20 Scott A, Shiell A, King M. Is general practitioner's decision making associated with patient socio-economic status ? Soc Sci Med 1996;42:35-46.
21 Greenwood D, PackhamC, Muir K, et al. How do economic status and social support influence survival after initial recovery from acute myocardial infarction Soc Sci Med 1995;40:639-47.

22 Ruberman W, Weinblatt E, Goldberg JD, et al. Psychosocial influences on mortality after myocardial infarction. $\mathrm{N} \mathrm{Engl}$ f Med 1984;311:552-9.

23 Williams RB, Barefoot JC, Califf RM, et al. Prognostic importance of social and economic resources among medically treated patients with angiographically documented coronary artery disease. fAMA 1992;267:520-4.

24 Pilote L, Califf RM, Sapp S, et al, for the GUSTOinvestigators. Regional variation across the United States in the management of acute myocardial infarction. $N$ Engl $\mathcal{F}$ Med 1995;333:565-72.

25 Lang T, Lombrail P, Fouriaud C, et al. Hôpital, médecine du travail et correction des inégalités dans le domaine de la prévention. Rev Epidemiol Sante Publique 1990;38:281-6.

26 Keskimaki I, Salinto M, Aro S. Socioeconomic equity in Finnish hospital care in relation to need. Soc Sci Med 1995; 41:425-31.

27 Keskimaki I, Salinto M, Aro S. Private medicine and socioeconomic differences in the rates of common surgical procedures in Finland. Health Policy 1996;36:245-59.

28 Gaffney B, Kee F. Are the economically active more deserving? Br Heart f 1995; 73:385-9. 